\title{
Fibroblast-like synovial cell production of extra domain A fibronectin associates with inflammation in osteoarthritis
}

Tue W. Kragstrup ${ }^{1,2,3,4^{*}}$ (D), Dong H. Sohn ${ }^{1,2,5}$, Christin M. Lepus ${ }^{1,2}$, Kazuhiro Onuma ${ }^{1,2}$, Qian Wang ${ }^{1,2}$, William H. Robinson ${ }^{1,2}$ and Jeremy Sokolove $e^{1,2}$

\begin{abstract}
Background: The pathophysiology of osteoarthritis $(\mathrm{OA})$ involves wear and tear, and a state of low-grade inflammation. Tissue repair responses include transforming growth factor beta (TGF $\beta$ )-induced myofibroblast production of extracellular matrix. Fibronectins are an essential part of the extracellular matrix, and injection of fibronectin fragments into rabbit joints is a previously established animal model of OA. Fibronectin containing the ED-A domain is currently being used as drug delivery target in the development of anti-inflammatory drugs (e.g. Dekavil).

Methods: In this study, samples of synovial membrane were obtained from patients with knee OA undergoing joint replacement surgery. Immunostaining for ED-A fibronectin and the myofibroblast marker alpha smooth muscle actin (aSMA) was performed on fibroblast-like synovial cells (FLS) and synovial membranes. RAW 264.7 macrophages were incubated with recombinant ED-A fibronectin.
\end{abstract}

Results: The staining of ED-A fibronectin in OA FLS was increased by TGF $\beta$ but not by TNFa, lipopolysaccharide, or IL-6 $(n=3)$. ED-A fibronectin co-stained with the myofibroblast marker aSMA in both the OA FLS $(n=3)$ and in the OA synovial membranes $(n=8)$. ED-A fibronectin staining was associated with both number of lining layer cells (rho $=0.85$ and $p=0.011$ ) and sublining cells (rho $=0.88$ and $p=0.007$ ) in the OA synovium $(n=8)$, and co-distributed with TNFa $(n=5)$. Recombinant ED-A fibronectin increased the production of TNFa by RAW 264.7 macrophages $(n=3)$.

Conclusions: The disease process in OA shares features with the chronic wound healing response. Our findings support utilizing ED-A fibronectin for drug delivery or therapeutic targeting to reduce pro-inflammatory responses in $\mathrm{OA}$.

Keywords: Osteoarthritis, Fibronectin, Myofibroblast, Inflammation, Arthritis, Synovitis, Synoviocyte, Drug delivery

\section{Background}

Osteoarthritis (OA) is a very common disease affecting approximately $60 \%$ of the population by age 65 years with no current therapeutics approved for preventing disease progression. The disease is often restricted to a few joints and with very low systemic inflammatory burden. Due to the slow progression of the disease there is a need for treatments with a very mild adverse effect profile. The extracellular matrix molecule fibronectin

\footnotetext{
* Correspondence: kragstrup@biomed.au.dk

'Department of Immunology and Rheumatology, Stanford University, Stanford, CA, USA

${ }^{2}$ VA Palo Alto Health Care System, Palo Alto, CA, USA

Full list of author information is available at the end of the article
}

containing the ED-A domain is currently being used as drug delivery target in the development of antiinflammatory drugs (e.g. Dekavil) $[1,2]$. Here, we show that the expression of fibronectin containing ED-A is closely linked to the pathogenic processes in OA. This could translate into the development of drugs suited for the treatment of OA.

The pathogenesis of OA involves wear and tear and a state of low-grade inflammation, which has generated the hypothesis that OA could be a chronic wound [3-5]. Thus, wear and tear leads to tissue degradation followed by tissue repair responses including transforming growth factor beta (TGF $\beta$ )-induced myofibroblast production of extracellular matrix [6]. Extracellular matrix molecules

(c) The Author(s). 2019 Open Access This article is distributed under the terms of the Creative Commons Attribution 4.0 International License (http://creativecommons.org/licenses/by/4.0/), which permits unrestricted use, distribution, and reproduction in any medium, provided you give appropriate credit to the original author(s) and the source, provide a link to the Creative Commons license, and indicate if changes were made. The Creative Commons Public Domain Dedication waiver (http://creativecommons.org/publicdomain/zero/1.0/) applies to the data made available in this article, unless otherwise stated. 
and breakdown products can then function as danger associated molecular patterns leading to activation of the immune system through activation of Toll-like receptors (TLRs) on macrophages [7].

Fibronectins (fibronectins) are an essential part of the extracellular matrix. The active fibronectins consist of several isoforms and peptide fragments with individual functions [8]. Fibronectin produced by fibroblasts is thus a result of both alternative splicing potentially incorporating extra domain A (ED-A) or ED-B and proteolytic cleavage by enzymes such as plasmin and thermolysin [9].

The association between fibronectin and OA is already established [10,11]. Injection of fibronectin fragments in rabbit joints lead to many characteristics of OA including cartilage degradation and bony spur formation and is now an established animal model of OA [12]. Fibronectin fragments are present in OA synovial fluid and have been shown to induce pro-inflammatory cytokines and matrix metalloproteinases [13, 14]. However, the mechanisms coupling fibronectin fragments and $\mathrm{OA}$ are not fully understood. The fibronectin fragments containing the ED-A domain are of particular interest because they show properties with possible implications for both immune activation and joint damage in OA [15]. These fragments have thus recently been shown to function as TLR-4 agonists [16], and synovial fluid levels correlate with establishment of disease and radiographic progression in rheumatoid arthritis [17, 18]. Also, ED-A fibronectin is produced by myofibroblasts and are essential for normal wound healing fitting the theory of OA as a chronic wound [19-21].

In this study, we hypothesize that ED-A fibronectin fragments represent a factor transducing repair mechanisms with inflammatory signals in OA. The aim was to describe the localization and production of ED-A FN in the OA synovium and to explore associations between ED-A FN and inflammation.

\section{Methods}

\section{Osteoarthritis patients}

Samples were obtained from 12 patients with knee OA undergoing joint replacement surgery. Patients were diagnosed with knee OA of Kellgren-Lawrence score 2 to 4 according to the 1985 criteria of the American Rheumatism Association [22, 23]. The number of patients used in each experiment is stated in the figure legends.

\section{Ethics, consent and permissions}

Samples were obtained under protocols approved by the Stanford University Institutional Review Board and with the patients' informed consent.

\section{Isolation of synovial tissue and synovial FLSs}

Synovial tissue samples for immunofluorescence were snap frozen in Tissue-Tek. FLSs for immunofluorescence were isolated after enzymatic digestion of the tissue. Synovium was minced with sterile scissors digested with collagenase grade II (Clostridium histolyticum) in DMEM and antibiotics supplemented with 5\% fetal bovine serum (FBS). The resulting cell suspension was pipetted through a $70 \mu \mathrm{m}$ mesh and centrifuged at $250 \mathrm{~g}$ for $10 \mathrm{~min}$. The cells were washed and incubated at $37^{\circ} \mathrm{C}$ and $5 \% \mathrm{CO}_{2}$. Cells were passaged using trypsin and used at passage 5 .

\section{Immunoflourescence of osteoarthritis FLSs}

Immunoflourescence of FLSs were done as previously described [24]. Sterile glass slides were placed in 24-well cell culture plates. FLSs were then seeded at a concentration of $5.0 \times 10^{4}$ cells $/ \mathrm{mL}$ in DMEM and antibiotics supplemented with 5\% FBS and incubated for $24 \mathrm{~h}$ at $37^{\circ} \mathrm{C}$. The cells were either untreated or stimulated with TGF $\beta 1$ at $5 \mathrm{ng} / \mathrm{ml}$, TNF $\alpha$ (PeproTech) at $10 \mathrm{ng} / \mathrm{mL}$, lipopolysaccharide (LPS) (Sigma) at $100 \mathrm{ng} / \mathrm{ml}$, or IL-6 (PeproTech) at $10 \mathrm{ng} / \mathrm{ml}$ as done previously [25-27]. Cells were fixed with $4 \%$ paraformaldehyde and then incubated for $30 \mathrm{~min}$ at room temperature with PBS with $0.05 \%$ Tween 20 , $1 \%$ bovine serum albumin, 5\% normal goat serum, and $0.03 \% \mathrm{NaN}_{3}$. Cells were stained with rabbit polyclonal anti-EDA fibronectin (kind gift from Digna Bioscience, Madrid, Spain) and mouse IgG2a anti$\alpha$ SMA (clone 1A4, R\&D Systems). Rabbit polyclonal isotype and mouse $\operatorname{IgG} 2 \mathrm{a}$ isotype were used as negative controls. Goat anti-rabbit alexa 488 and goat anti-mouse IgG2a alexa 555 were used as secondary antibodies (both Thermo Fischer). Wells were washed twice, and glass slides were mounted with Prolong Gold Antifade with DAPI (Thermo Fischer). All micrographs were collected by using a Zeiss LSM-710 confocal microscope. ED-A fibronectin positive cells and total cells were counted for each culture condition in two fields of view counting at least 150 cells for each experimental condition.

\section{Immunoflourescence of osteoarthritis synovial membranes}

Synovial tissue samples for immunofluorescence were snap frozen in Tissue-Tek and cut in sections of $10 \mu \mathrm{m}$ using a cryostat and sections were fixed with $4 \%$ paraformaldehyde and then incubated for $30 \mathrm{~min}$ at room temperature with PBS with $0.05 \%$ Tween $20,1 \%$ bovine serum albumin, 5\% normal goat serum, and 0.03\% NaN3. Synovial tissue sections were stained with rabbit polyclonal anti-EDA fibronectin (kind gift from Digna Bioscience, Madrid, Spain), mouse IgG2a anti- $\alpha$ SMA (clone 1A4, R\&D Systems), rabbit polyclonal anti- $\alpha \mathrm{SMA}$ (Abcam), mouse IgG2a anti-CD45 (clone F10-89-4, 
Abcam), mouse IgG1 anti-CD31 (clone JC70A, Dako), and rabbit polyclonal anti-TNF $\alpha$ (Abcam). Rabbit polyclonal isotype, mouse IgG2a isotype, mouse IgG1 isotype, and mouse IgG2b isotype were used as negative controls. Goat anti-rabbit alexa 488, goat anti-mouse IgG2a alexa 555, goat anti mouse IgG1 alexa 647, and goat anti-mouse IgG alexa 555 were used as secondary antibodies (all Thermo Fischer). Slides were washed twice, and glass slides were placed in $2 \mu \mathrm{L}$ of Prolong Gold Antifade with DAPI (Thermo Fischer) and allowed to dry overnight. All micrographs were collected with a Zeiss LSM-710 confocal microscope. Micrographs were analyzed using ImageJ software (NIH). The area with ED-A staining was found and calculated as a percentage of total area. The area with DAPI staining in the sublining layer was found and calculated as a percentage of total area. The lining layer cell thickness was counted.

\section{Stimulation of RAW 264.7 macrophages}

RAW 264.7 macrophages were cultured with recombinant human ED-A fibronectin fragment (kind gift from Digna Bioscience, Madrid, Spain) at $10 \mu \mathrm{g} / \mathrm{ml}$. For confirmation that endotoxin contamination was not a confounding factor, 1) the cells were cultured in the presence of the LPS blocking polypeptide polymyxin B at $15 \mu \mathrm{g} / \mathrm{ml}$ (Sigma-Aldrich), 2) ED-A fibronectin was pretreated with boiling for $30 \mathrm{~min}$, or 3) ED-A fibronectin was pretreated with proteinase $\mathrm{K}$ at $20 \mu \mathrm{g} / \mathrm{ml}$. For each experiment, an untreated cell culture with the same number of cells in medium without stimulants was used for comparison and a culture stimulated with LPS at a concentration of $100 \mathrm{ng} / \mathrm{ml}$ was used as a positive control. Cells were cultured for $24 \mathrm{~h}$ at $37^{\circ} \mathrm{C}$ in a humidified incubator with $5 \% \mathrm{CO}_{2}$ without changing of medium. After incubation, supernatants were stored frozen at $80^{\circ} \mathrm{C}$ for later assessment.

\section{Enzyme linked immunosorbent assay}

Supernatants from RAW 264.7 macrophage cultures were analyzed for TNFa concentration by ELISA (PeproTech) according to the manufacturors instructions.

\section{Statistics}

Statistical analyses were performed using GraphPad Prism 6.0 for Mac (GraphPad Software). Data with EDA FN production by OA FLSs were presented as ratios of $\mathrm{ED}^{-\mathrm{A}^{+}}$cells divided by total cells. Ratios were $\log$ transformed and analyzed with the paired t-test. Correlations of ED-A FN staining and histological features of the synovial membrane were made using Spearman's Rho. Data with TNFo production by RAW 264.7 cells after ED-A FN stimulation were presented as ratios of stimulated cells divided by untreated cells. In all tests, the level of significance was a two-sided $P$ value of less than 0.05 . The statistics used in each experiment is also stated in the figure legends.

\section{Results \\ ED-A fibronectin is produced by OA FLSs in response to TGF $\beta$}

We first tested whether ED-A fibronectin is produced by OA FLSs in response to TGF $\beta$, TNF $\alpha$, LPS, and IL-6. OA FLSs were incubated with these stimulators and stained for ED-A fibronectin and the myofibroblast marker $\alpha$ SMA. Spontaneous production of ED-A fibronectin was found in a small number of cells in untreated cultures (Fig. 1a). ED-A fibronectin co-stained with aSMA (Fig. 1a). The number of ED-A FN positive cells divided by total number of cells was increased by TGF $\beta$ $(p=0.046)(n=3)$ (Fig. 1b-c). There was no change in the number of ED-A fibronectin positive OA FLSs when using TNF $\alpha(p=0.5)$, LPS $(p=0.6)$, or IL-6 $(p=0.9)$ (Fig. $1 \mathrm{~b}-\mathrm{c})$. No signal was detected when staining with negative control isotype antibody (Fig. 1b).

\section{ED-A fibronectin is located to aSMA positive myofibroblasts in $\mathrm{OA}$ synovium}

We then tested whether ED-A fibronectin also codistributed with $\alpha \mathrm{SMA}$ in the OA synovial membrane. ED-A fibronectin was found in the synovium from all OA patients $(n=8)$ (Fig. 2a). The ED-A fibronectin staining was most intense in lining layer cells while aSMA staining was most intense in cells surrounding CD31 positive blood vessels (Fig. 2b). However, most ED-A fibronectin positive cells were also to some extent $\alpha$ SMA positive in all the stained synovial membranes $(n=3)$ (Fig. 2c).

\section{ED-A fibronectin associates with increased number of lining layer cells and sublining cells in $O A$ synovium} Next, we tested whether ED-A fibronectin expression associates with number of cells in the OA synovium. Therefore, we first analyzed the association between the degree of ED-A fibronectin staining and the number of lining layer cells and sublining cells in OA synovium. The ED-A fibronectin staining associated with both number of lining layer cells (rho $=0.85$ and $p=0.011$ ) and sublining cells (rho $=0.88$ and $p=0.007$ ) in OA synovium $(n=8)$ (Fig. 3a-c).

\section{ED-A fibronectin is located to areas of TNFa staining in OA synovium}

We then analyzed the OA synovial membranes for codistribution of ED-A fibronectin and TNF $\alpha$. ED-A fibronectin and TNF $\alpha$ were stained on serial slides. ED-A fibronectin co-distributed with TNF $\alpha$ in all stained synovial membranes $(n=5)$ (Fig. 4a-b). The staining of TNF $\alpha$ was mostly located to cells in close proximity to 

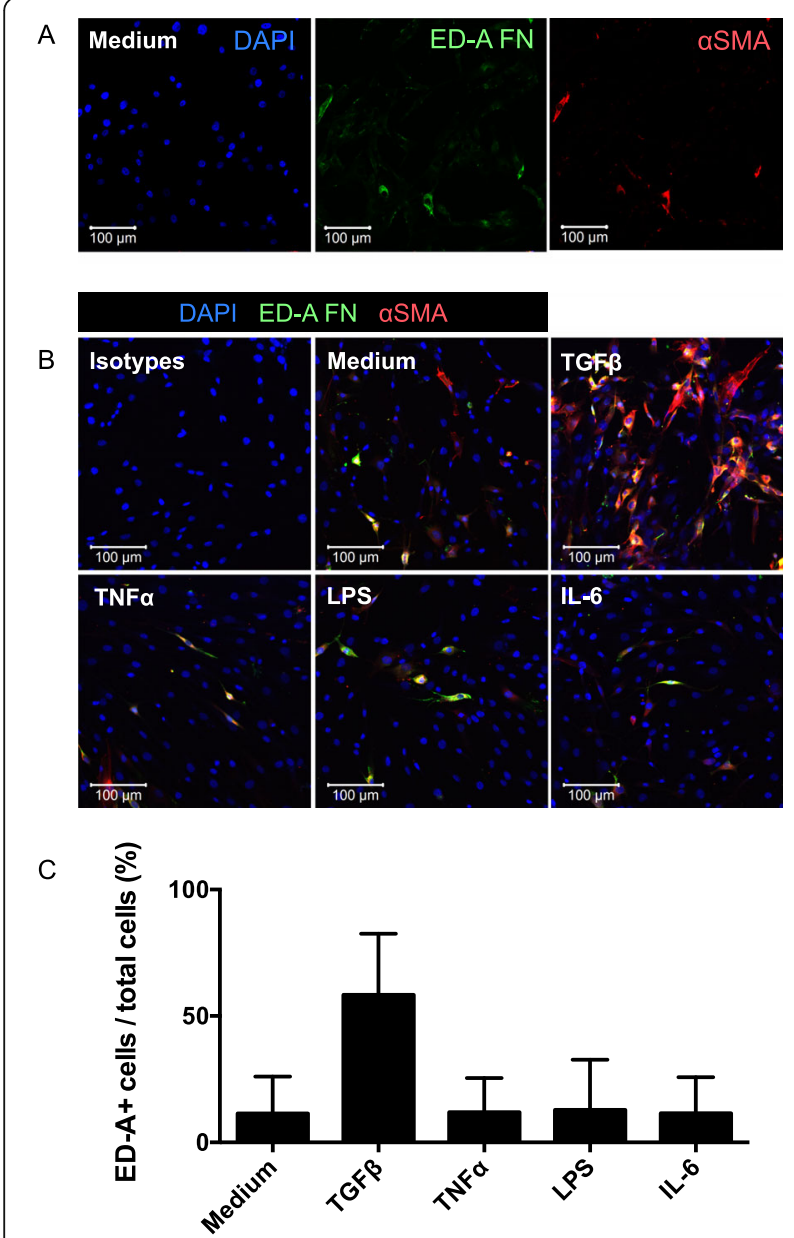

Fig. 1 ED-A fibronectin production by OA FLSs. a and $\mathbf{b}$.

Representative confocal microscopy images of aSMA (red) and ED-A fibronectin (green) in OA FLS cultures incubated with medium, TGF $\beta$, TNFa, LPS, or IL-6 $(n=3)$. No staining was seen using isotype control antibodies. c ED-A fibronectin was expressed as a ratio of ED-A fibronectin positive cells divided by the total cell count. Data were log transformed and analyzed with the paired t-test. Bars indicate the median and whiskers indicate the IQR. ${ }^{*} P<0.05$

the ED-A fibronectin positive cells but not specifically to the ED-A fibronectin positive cells.

\section{Recombinant ED-A fibronectin increases the secretion of TNFa by RAW 264.7 macrophages}

We now tested whether the association between ED-A fibronectin and TNF $\alpha$ in the synovial membrane could be caused by a stimulatory effect of ED-A fibronectin on TNF $\alpha$ production by macrophages. Recombinant ED-A fibronectin increased the production of TNF $\alpha$ from RAW 264.7 cells using a concentration of $10 \mu \mathrm{g} / \mathrm{ml}(p<$ $0.0001)(n=9)$ (Fig. 5). The stimulatory effect of ED-A FN was not reduced with the LPS-blocking polypeptide polymyxin $\mathrm{B}(p=0.69)$. In contrast, the stimulatory effect of LPS was significantly decreased with polymyxin B $(p=0.0031)(n=3)$ (Fig. 5). The stimulatory effect of ED-A fibronectin was reduced when treating the ED-A fibronectin with proteinase $\mathrm{K}(p=0.001)$ or heat $(p=$ 0.0068) $(n=3)$ (Fig. 5). Taken together, this indicates that the effect of ED-A fibronectin was not caused by contamination with LPS.

\section{Discussion}

$\mathrm{OA}$ is a common joint disease involving wear and tear and low-grade inflammation. The disease pathogenesis has thus been speculated to resemble a pathogenic wound healing response $[3,4]$. Here, we show that ED-A fibronectin could be part of such pathogenic wound healing mechanisms.

First, we studied expression of ED-A fibronectin in OA. We found formation of ED-A fibronectin in $\alpha \mathrm{SMA}$ positive myofibroblasts isolated from OA synovial tissue, induction of ED-A fibronectin production by TGF $\beta$, and co-localization of ED-A fibronectin and $\alpha \mathrm{SMA}$ in the OA synovium. This is in line with previous findings suggesting that ED-A fibronectin is expressed in TGF $\beta$ induced myofibroblast differentiation [8], and that TGF $\beta$ is increased in OA synovial fluid [28]. Further, the role of a general wound healing response in OA is supported by findings of increased fibronectin secretion after blunt cartilage trauma in a bovine model of OA [29], increased fibrosis and joint stiffening in OA [30], and by the protective effect of blocking TGF $\beta$ in experimental OA in mice [6].

Then, we studied the possible association between EDA fibronectin and inflammation in OA. We found that ED-A fibronectin is associated with lining layer thickness and sublining cellular density in the OA synovium. This is in line with previous findings of high ED-A fibronectin expression in rheumatoid arthritis and in proliferative regions of OA [31, 32]. The association between ED-A fibronectin expression and cellular density and presence of inflammatory molecules in the OA synovium is of particular interest because there are currently ongoing studies of utilizing ED-A fibronectin as a drug delivery target in rheumatoid arthritis and other diseases [33]. E.g., Dekavil is a drug combining a human F8 antibody specific to the ED-A domain of fibronectin fused to the anti-inflammatory cytokine IL-10 [1, 2]. A recent study, only found small amounts of ED-A fibronectin mRNA in OA synovium [34]. This suggests that the formation of ED-A fibronectin might rather be a result of enzymatic digestion (e.g. by plasmin or thermolysin) or folding than synthesis.

Macrophages are known to be part of the cellular infiltrate in the OA synovium [35]. We therefore studied the effect of recombinant ED-A fibronectin on macrophage production of these pro-inflammatory mediators. The recombinant ED-A fibronectin fragment used in these 

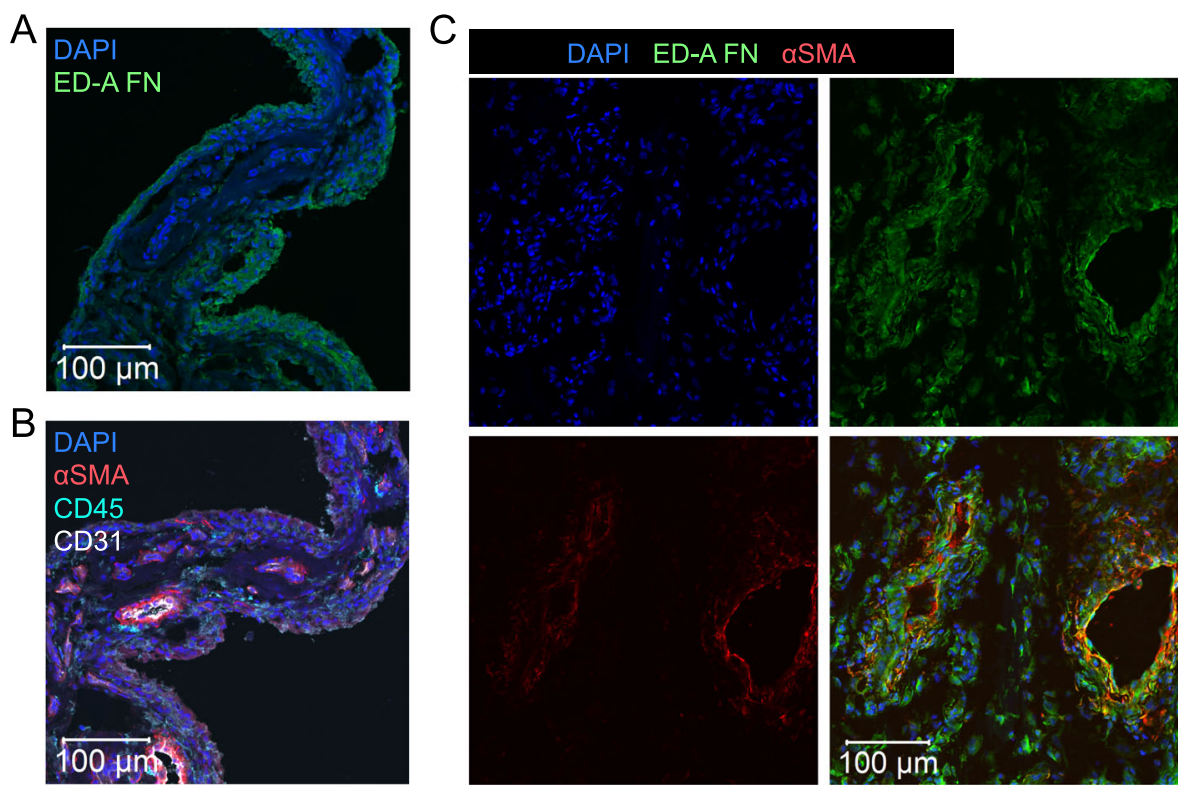

Fig. 2 ED-A fibronectin expression in OA synovium. a and b Representative confocal microscopy images of CD45, CD31, aSMA and ED-A fibronectin in OA synovium ( $n=8)$. c Representative confocal microscopy images of ED-A fibronectin co-localization with aSMA $(n=3)$

experiments stimulated the production of TNF $\alpha$ by RAW 264.7 macrophages. The stimulatory effect was not decreased by the LPS-blocking polypeptide polymyxin $\mathrm{B}$ and could be diminished by proteinase $\mathrm{K}$ treatment or heat. This indicates that the effect of the ED-A FN fragments was not caused by contamination with LPS. This finding was supported by the co-distribution of ED-A FN with TNF $\alpha$ in the OA synovial membrane. Further, our study is in line with previous findings of ED-A fibronectin induced increase of IL- $1 \beta$ production by synovial cells [36]. The stimulatory effects could be due to ED-A fibronectin binding to TLR-4 as previously reported [16].

There are several limitations to this study. Here, only TGF $\beta$, TNF $\alpha$, LPS, and IL- 6 were studied for potential ED-A FN inducing properties in OA FLSs. It is therefore not known whether other cytokines or other factors could induce ED-A FN production in these cells. In the assay using RAW 264.7 macrophages, the positive LPS control stimulation gave very variable results. However, the treatment effect of ED-A FN was seen in all experiments. Therefore, the variations do not seem to have
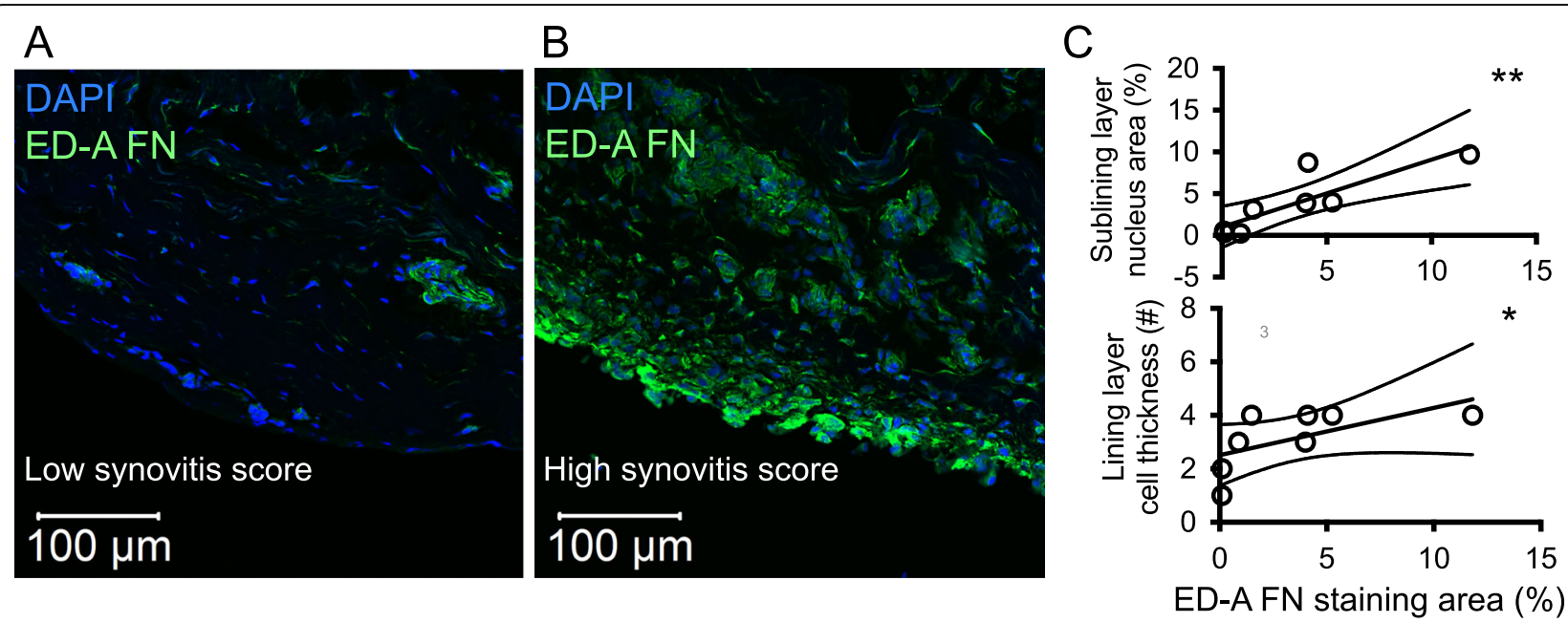

Fig. 3 ED-A fibronectin expression and degree of synovitis in OA synovium. a and $\mathbf{b}$ Representative confocal microscopy images of ED-A fibronectin staining and synovitis score $(n=8)$. c ED-A fibronectin expression associated with cell infiltration in the sublining layer and cell thickness of the lining layer. Data were analyzed using the Spearman's Rho. ${ }^{*} P<0.05,{ }^{*} P<0.01$ 


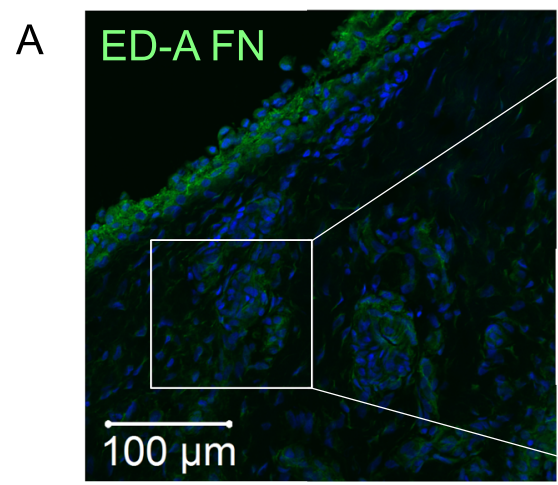

B

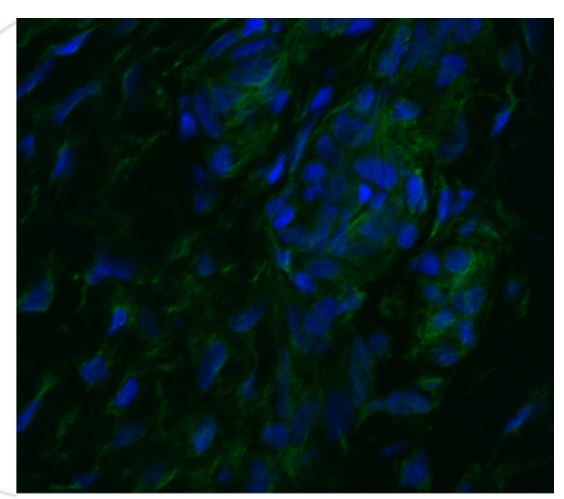

C

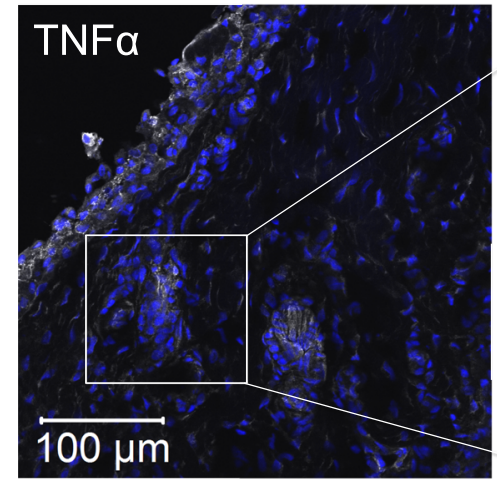

D

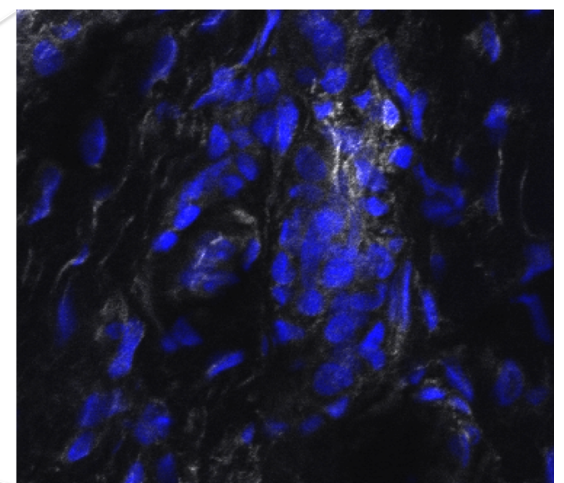

Fig. 4 Co-localization of ED-A fibronectin. a-d Representative confocal microscopy images of localization of ED-A fibronectin and TNFa in OA synovium $(n=5)$. TNFa staining was found in areas with ED-A fibronectin staining. $\mathbf{c}$ and $\mathbf{d}$ Close-up of the white boxes on original images

influenced the results. ED-A FN and LPS were both used in only one concentration. Therefore, no comparison can be made from this study. Further, only TNF $\alpha$ was measured as the downstream effect of ED-A FN in macrophages. Other cytokines or chemokines could likely be altered with ED-A FN stimulation. It is also not known from this study how ED-A FN affects human OA macrophages. Further, the present study is limited by the in vitro design. It would be interesting to see the treatment effect of ED-A FN targeting drugs in a mouse model of OA. Finally, this study is limited by a rather small sample size.

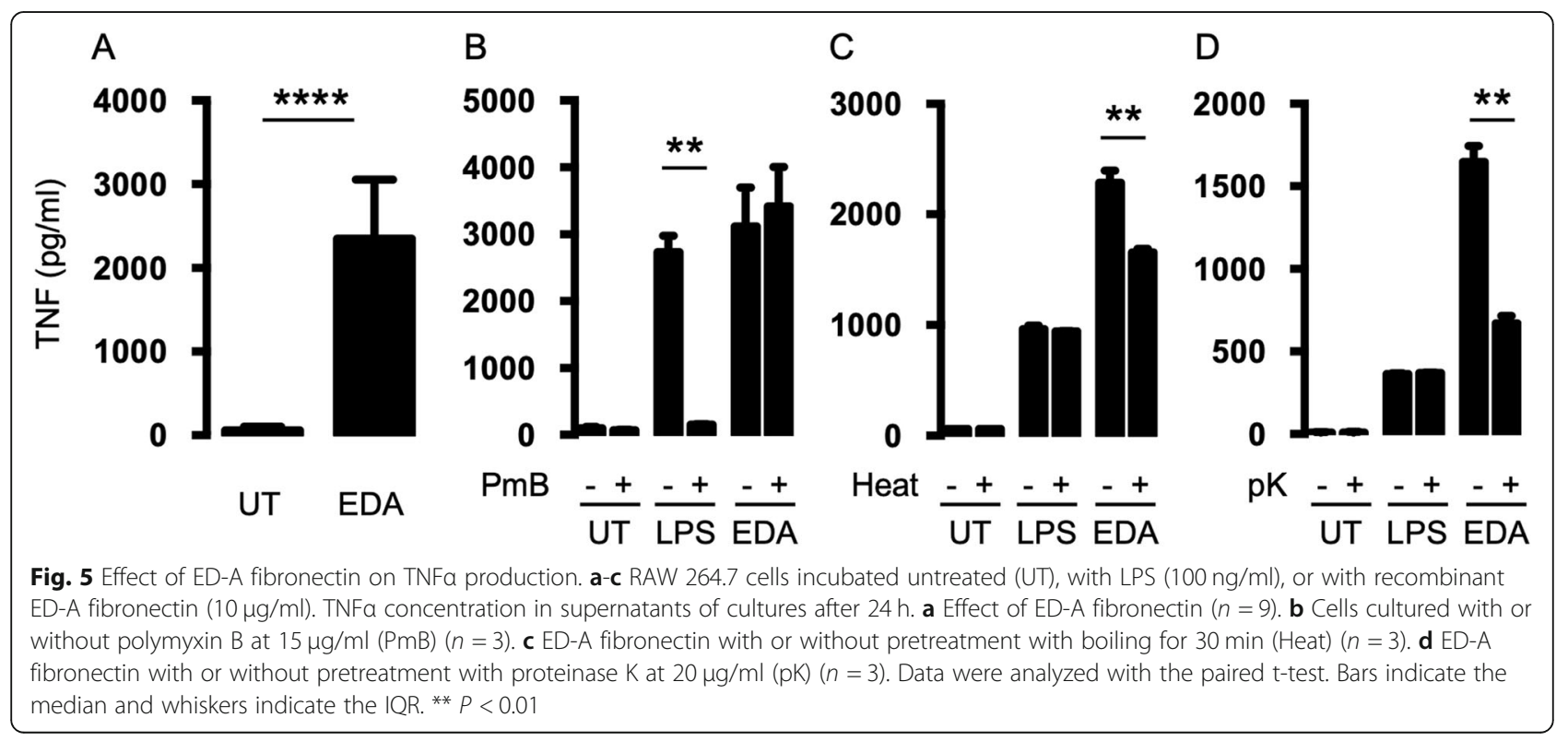


There is an unmet therapeutic need preventing OA disease progression. This study supports that ED-A fibronectin could be a target for drug delivery to the inflamed joint or that the formation of ED-A fibronectin or the enzymatic fragmentation of fibronectin could be novel therapeutic targets in OA.

\section{Conclusions}

Taken together, we show that myofibroblasts produce ED-A fibronectin and that ED-A fibronectin stimulates TNF $\alpha$ production by macrophages possibly promoting inflammation in OA.

\section{Abbreviations}

ED-A: ED-A domain; FBS: Fetal bovine serum; FLS: Fibroblast-like synovial cells; IL: Interleukin; IQR: Interquartile range; LPS: Lipopolysaccharide; OA: Osteoarthritis; PBS: Phosphate buffered saline; TGF 3 : Transforming growth factor beta; TLR: Toll-like receptor; TNFa: Tumour necrosis factor alpha; UT: Untreated; aSMA: Alpha smooth muscle actin

\section{Acknowledgements}

The work has been presented at the annual European League Against Rheumatism meeting in 2017 and at the annual American Congress of Rheumatology meeting in 2017

\section{Authors' contributions}

All authors were involved in drafting the article or revising it critically for important intellectual content, and all authors approved the final version to be published. Study conception and design: TWK, WHR, JS. Acquisition of data: TWK, DHS, KO, CML, QW, JS. Analysis and interpretation of data: TWK, DHS, WHR, JS. All authors read and approved the final manuscript.

\section{Funding}

This work was supported by the Danish Research council and the Faculty of Health at Aarhus University. The authors received no specific funding for this work. The funding bodies did not play any role in the design of the study and collection, analysis, and interpretation of data and in writing the manuscript.

\section{Availability of data and materials}

Please contact corresponding author TWK for data requests.

\section{Ethics approval and consent to participate}

Samples were obtained under protocols approved by the Stanford University Institutional Review Board. All study participants gave written consent to participate.

\section{Consent for publication}

All study participants gave verbal consent for publication.

\section{Competing interests}

The authors declare that they have no competing interests.

\section{Author details \\ 'Department of Immunology and Rheumatology, Stanford University, Stanford, CA, USA. VA Palo Alto Health Care System, Palo Alto, CA, USA. ${ }^{3}$ Department of Biomedicine, Aarhus University, Wilhelm Meyers Allé 4, DK-8000 Aarhus C, Denmark. ${ }^{4}$ Department of Rheumatology, Aarhus University Hospital, Aarhus, Denmark. ${ }^{5}$ Department of Microbiology and Immunology, Pusan National University School of Medicine, Yangsan, Republic of Korea.}

Received: 25 April 2019 Accepted: 10 October 2019

Published online: 02 December 2019

\section{References}

1. Schwager K, Kaspar M, Bootz F, Marcolongo R, Paresce E, Neri D, et al. Preclinical characterization of DEKAVIL (F8-IL10), a novel clinical-stage immunocytokine which inhibits the progression of collagen-induced arthritis. Arthritis Res Ther. 2009;11:R142.

2. Galeazzi M, Bazzichi L, Sebastiani GD, Neri D, Garcia E, Ravenni N, et al. A phase IB clinical trial with Dekavil (F8-IL10), an immunoregulatory "armed antibody" for the treatment of rheumatoid arthritis, used in combination wilh methotrexate. Isr Med Assoc J. 2014;16:666.

3. Scanzello CR, Plaas A, Crow MK. Innate immune system activation in osteoarthritis: is osteoarthritis a chronic wound? Curr Opin Rheumatol. 2008; 20:565-72.

4. Sokolove J, Lepus CM. Role of inflammation in the pathogenesis of osteoarthritis: latest findings and interpretations. Ther Adv Musculoskelet Dis. 2013;5(2):77-94

5. Robinson WH, Lepus CM, Wang Q, Raghu H, Mao R, Lindstrom TM, et al. Low-grade inflammation as a key mediator of the pathogenesis of osteoarthritis. Nat Rev Rheumatol. 2016:12:580-92.

6. Scharstuhl A, Vitters EL, van der Kraan PM, van den Berg WB. Reduction of osteophyte formation and synovial thickening by adenoviral overexpression of transforming growth factor $\beta /$ bone morphogenetic protein inhibitors during experimental osteoarthritis. Arthritis Rheum. 2003:48:3442-51.

7. Erridge C. Endogenous ligands of TLR2 and TLR4: agonists or assistants? J Leukoc Biol. 2010;87:989-99.

8. White ES, Muro AF. Fibronectin splice variants: understanding their multiple roles in health and disease using engineered mouse models. IUBMB Life. 2011;63:538-46.

9. Gonzales-Gronow M, Enghild JJ, Pizzo SV. Streptokinase and human fibronectin share a common epitope: implications for regulations of fibrinolysis and rheumatoid arthritis. Biochim Biophys Acta Mol Basis Dis. 1993;1180:283-8.

10. Peters JH, Loredo GA, Benton HP. Is osteoarthritis a 'fibronectin-integrin imbalance disorder'? Osteoarthr Cartil. 2002:10:831-5.

11. Barilla ML, Carsons SE. Fibronectin fragments and their role in inflammatory arthritis. Semin Arthritis Rheum. 2000;29:252-65.

12. Homandberg GA, Meyers R, Williams JM. Intraarticular injection of fibronectin fragments causes severe depletion of cartilage proteoglycans in vivo. J Rheumatol. 1993;20:1378-82.

13. Xie $\mathrm{DL}$, Meyers $\mathrm{R}$, Homandberg GA. Fibronectin fragments in osteoarthritic synovial fluid. J Rheumatol. 1992;19:1448-52.

14. Homandberg GA, Hui F. Association of proteoglycan degradation with catabolic cytokine and stromelysin release from cartilage cultured with fibronectin fragments. Arch Biochem Biophys. 1996:334:325-31.

15. Carsons S. Extra domain-positive fibronectins in arthritis: wolf in sheep's clothing? Rheumatology (Oxford). 2001;40:721-3.

16. Okamura Y, Watari M, Jerud ES, Young DW, Ishizaka ST, Rose J, et al. The extra domain A of fibronectin activates toll-like receptor 4. J Biol Chem. 2001;276:10229-33.

17. Przybysz M, Borysewicz K, Katnik-Prastowska I. Differences between the early and advanced stages of rheumatoid arthritis in the expression of EDAcontaining fibronectin. Rheumatol Int. 2009;29:1397-401.

18. Shiozawa K, Hino K, Shiozawa S. Alternatively spliced EDA-containing fibronectin in synovial fluid as a predictor of rheumatoid joint destruction. Rheumatology (Oxford). 2001:40:739-42.

19. Muro AF, Chauhan AK, Gajovic S, laconcig A, Porro F, Stanta G, et al. Regulated splicing of the fibronectin EDA exon is essential for proper skin wound healing and normal lifespan. J Cell Biol. 2003;162:149-60.

20. Ffrench-Constant C, Van de Water L, Dvorak HF, Hynes RO. Reappearance of an embryonic pattern of fibronectin splicing during wound healing in the adult rat. J Cell Biol. 1989;109:903-14.

21. Serini G, Bochaton-Piallat ML, Ropraz P, Geinoz A, Borsi L, Zardi L, et al. The fibronectin domain ED-A is crucial for myofibroblastic phenotype induction by transforming growth factor-beta1. J Cell Biol. 1998;142:873-81.

22. Kellgren JH, Lawrence JS. Radiological assessment of osteoarthrosis. Ann Rheum Dis. 1957:16:494-502.

23. Altman R, Asch E, Bloch D, Bole G, Borenstein D, Brandt $K$, et al. Development of criteria for the classification and reporting of osteoarthritis. Classification of osteoarthritis of the knee. Diagnostic and therapeutic criteria committee of the American Rheumatism Association. Arthritis Rheum. 1986;29:1039-49.

24. Kragstrup TW, Jalilian B, Hvid M, Kjærgaard A, Østgård R, Schiøttz Christensen B, et al. Decreased plasma levels of soluble CD18 link leukocyte infiltration with disease activity in spondyloarthritis. Arthritis Res Ther. 2014;16:R42 
25. Stougaard J, Lomholt S, Ommen P, Kelsen J, Kragstrup TW. The antifibrotic drug pirfenidone inhibits spondyloarthritis fibroblast-like synoviocytes and osteoblasts in vitro. BMC Rheumatol. 2018;2:33.

26. Heftdal LD, Andersen T, Jæhger D, Woetmann A, Østgård R, Kenngott EE, et al. Synovial cell production of IL-26 induces bone mineralization in spondyloarthritis. J Mol Med. 2017;95:779-87.

27. Kragstrup TW, Andersen MN, Schiøttz-Christensen B, Jurik AG, Hvid M, Deleuran B. Increased interleukin (IL)-20 and IL-24 target osteoblasts and synovial monocytes in spondyloarthritis. Clin Exp Immunol. 2017;189:342-51.

28. Schlaak JF, Pfers I, Meyer Zum Büschenfelde KH, Märker-Hermann E. Different cytokine profiles in the synovial fluid of patients with osteoarthritis, rheumatoid arthritis and seronegative spondylarthropathies. Clin Exp Rheumatol. 1996;14:155-62.

29. Ding L, Guo D, Homandberg GA, Buckwalter JA, Martin JA. A single blunt impact on cartilage promotes fibronectin fragmentation and upregulates cartilage degrading stromelysin-1/matrix metalloproteinase-3 in a bovine ex vivo model. J Orthop Res. 2014;32:811-8.

30. Hill CL, Hunter DJ, Niu J, Clancy M, Guermazi A, Genant H, et al. Synovitis detected on magnetic resonance imaging and its relation to pain and cartilage loss in knee osteoarthritis. Ann Rheum Dis. 2007;66:1599-603.

31. Hino K, Shiozawa S, Kuroki Y, Ishikawa H, Shiozawa K, Sekiguchi K, et al. Edacontaining fibronectin is synthesized from rheumatoid synovial fibroblastlike cells. Arthritis Rheum. 1995;38:678-83.

32. Kriegsmann J, Berndt A, Hansen T, Borsi L, Zardi L, Bräuer R, et al. Expression of fibronectin splice variants and oncofetal glycosylated fibronectin in the synovial membranes of patients with rheumatoid arthritis and osteoarthritis. Rheumatol Int. 2004;24:25-33.

33. Kumra H, Reinhardt DP. Fibronectin-targeted drug delivery in cancer. Adv Drug Deliv Rev. 2016;97:101-10

34. Scanzello CR, Markova DZ, Chee A, Xiu Y, Adams SL, Anderson G, et al. Fibronectin splice variation in human knee cartilage, meniscus and synovia membrane: observations in osteoarthritic knee. J Orthop Res. 2015;33:556-62.

35. Raghu $\mathrm{H}$, Lepus $\mathrm{CM}$, Wang $\mathrm{Q}$, Wong HH, Lingampalli N, Oliviero F, et al. CCL2/CCR2, but not CCL5/CCR5, mediates monocyte recruitment, inflammation and cartilage destruction in osteoarthritis. Ann Rheum Dis. 2017;76:914-22.

36. Saito S, Yamaji N, Yasunaga K, Saito T, Matsumoto S, Katoh M, et al. The fibronectin extra domain a activates matrix metalloproteinase gene expression by an interleukin-1-dependent mechanism. J Biol Chem. 1999; 274:30756-63.

\section{Publisher's Note}

Springer Nature remains neutral with regard to jurisdictional claims in published maps and institutional affiliations.

Ready to submit your research? Choose BMC and benefit from:

- fast, convenient online submission

- thorough peer review by experienced researchers in your field

- rapid publication on acceptance

- support for research data, including large and complex data types

- gold Open Access which fosters wider collaboration and increased citations

- maximum visibility for your research: over $100 \mathrm{M}$ website views per year

At $\mathrm{BMC}$, research is always in progress.

Learn more biomedcentral.com/submissions 